\title{
Effects of BP-14, a novel cyclin-dependent kinase inhibitor, on anaplastic thyroid cancer cells
}

\author{
LORENZO ALLEGRI $^{1}$, FEDERICA BALDAN ${ }^{1}$, CATIA MIO $^{1}$, CINZIA PUPPIN ${ }^{1}$, \\ DIEGO RUSSO $^{2}$, VLADIMIR KRYŠTOF ${ }^{3}$ and GIUSEPPE DAMANTE ${ }^{1,4}$
}

\author{
${ }^{1}$ Department of Medical and Biological Sciences, University of Udine, 33100 Udine; ${ }^{2}$ Department of Health Sciences, \\ University 'Magna Graecia' of Catanzaro, Catanzaro, Italy; ${ }^{3}$ Laboratory of Growth Regulators, Center of the Region Haná \\ for Biotechnological and Agricultural Research, Palacký University and Institute of Experimental Botany AS CR, \\ CZ-77111 Olomuc, Czech Republic; ${ }^{4}$ Institute of Medical Genetics, University \\ Hospital 'S. Maria della Misericordia', 33100 Udine, Italy
}

Received September 2,2015; Accepted October 16, 2015

DOI: 10.3892/or.2016.4614

\begin{abstract}
Anaplastic thyroid carcinoma (ATC) is an extremely aggressive human malignancy characterized by a marked degree of invasiveness, absense of features of thyroid differentiation and resistance to current medical treatment. It is well known that ATCs are characterized by deregulation of genes related to cell cycle regulation, i.e., cyclin-dependent kinases (CDKs) and endogenous cyclin-dependent kinase inhibitors (CDKIs). Therefore, in the present study, the effect of a novel exogenous cyclin-dependent kinase inhibitor, BP-14, was investigated in three human ATC cell lines. The ATC-derived cell lines FRO, SW1736 and 8505C were treated with BP-14 alone or in combination with the mTOR inhibitor everolimus. In all ATC cell lines, treatment with BP-14 decreased cell viability and, in two of them, BP-14 modified expression of genes involved in epithelial-mesenchymal transition. Thus, our data indicate that BP-14 is a potential new compound effective against ATC. Combined treatment with BP-14 and the mTOR inhibitor everolimus had a strong synergistic effect on cell viability in all three cell lines, suggesting that the combined used of CDK and mTOR inhibitors may be a useful strategy for ATC treatment.
\end{abstract}

\section{Introduction}

Thyroid cancers are the most common endocrine malignancies, and represent $\sim 1-1.5 \%$ of all tumor-related diseases (1). The overall 5-year survival of these tumors is $\sim 85-90 \%$, with the highest mortality rate reported for undifferentiated histotypes.

Correspondence to: Dr Giuseppe Damante, Department of Medical and Biological Sciences, University of Udine, Piazzale Kolbe 4, I-33100 Udine, Italy

E-mail: giuseppe.damante@uniud.it

Key words: mTOR, thyroid cancer, cell proliferation, synergy, CDK inhibitors
Thyroid cancers are classified as papillary (PTC), follicular (FTC), medullary (MTC) and anaplastic (ATC) carcinomas.

ATC is one of the most aggressive human malignancies. These tumors are poorly defined, fleshy masses with areas of necrosis and hemorrhage and there are no features of thyroid differentiation (2). The mechanisms underlying the development of ATCs are not completely understood. Available therapies for ATCs include chemotherapy, radiotherapy and surgery (3). Nonetheless, patients with ATC have a median survival of 5 months and less than $20 \%$ of patients survive 1 year post-diagnosis.

Mutations in genes encoding members of the RASMAPK-ERK and PI3K-AKT-mTOR signaling pathways are usually present in well-differentiated tumor components from which most ATCs develop (4-6). These signaling pathways are mainly involved in controlling cell survival, differentiation, proliferation and metabolism (7). Moreover, changes in the activity of these pathways can lead to drug resistance (8), which is a common feature of ATC. In addition, ATCs are characterized by other genetic and epigenetic aberrations, which cause deregulation of genes related to cell cycle regulation and its checkpoints, as well as alteration of chromosome segregation and spindle structure (9).

ATCs show frequent upregulation of cyclin-dependent kinase $(\mathrm{CDK})$ expression, mostly through inactivation of endogenous cyclin-dependent kinase inhibitors (CDKIs) including p27 $7^{\mathrm{KIP} 1}(10,11)$. Since CDKs and endogenous CDKIs are frequently deregulated in cancer cells, these have been considered as valid drug targets. A large number of synthetic CDKIs have been tested as anti-proliferative agents in cancer therapy, including roscovitine, one of the first CDKIs produced (12). Inhibitors of the kinase components of oncogenic pathways are also being currently explored as antiproliferative agents in several human neoplasms, including thyroid cancer (13).

In the present study, we investigated, in three ATC cell lines, the effects of a novel roscovitine derivate, named BP-14, whose efficacy has already been evaluated in hepatocellular carcinoma $(12,14)$. For this purpose, we evaluated cell 
viability, colony-forming capacity and expression of two genes related to epithelial-mesenchymal transition, $C D H 1$, a well known marker of epithelial phenotype, and vimentin (VIM), a type III intermediate filament (IF) protein that is expressed in mesenchymal cells (15). We, subsequently, studied the effects of a combined treatment using BP-14 and the mTOR inhibitor everolimus (RAD-001) on ATC cells, focusing on cell viability, migration and invasion abilities.

\section{Materials and methods}

Cell lines. The human thyroid cancer cell lines derived from anaplastic thyroid cancer (ATC) used in this study were: FRO (purchased from the European Collection of Cell Cultures, Salisbury, UK), SW1736 (obtained from Cell Lines Service $\mathrm{GmbH}$, Eppelheim, Germany) and 8505C (purchased from Sigma-Aldrich), all harboring a BRAF V600E mutation $(16,17)$. These cell lines were tested for being mycoplasma-free and authenticated by short tandem repeat analysis to be appropriate cell lines of thyroid cancer origin. FRO cells were grown in Dulbecco's modified Eagle's medium (DMEM; EuroClone, Milan, Italy), while SW1736 and 8505C cells were cultivated in Roswell Park Memorial Institute (RPMI)-1640 medium (EuroClone), in a humidified incubator $\left(5 \% \mathrm{CO}_{2}\right.$ in air at $37^{\circ} \mathrm{C}$; Eppendorf AG, Hamburg, Germany). Both media were supplemented with $10 \%$ fetal bovine serum (Gibco Invitrogen, Milan, Italy), $2 \mathrm{mM}$ L-glutamine (EuroClone) and $50 \mathrm{mg} / \mathrm{ml}$ gentamicin (Gibco Invitrogen). Cultured cells were treated with vehicle (DMSO; Sigma-Aldrich, St. Louis, MO, USA), BP-14 [prepared as described previously (12)] or RAD-001 (everolimus; Novartis, Basel, Switzerland).

Cell viability. To test cell viability, a 3-(4,5-dimethylthiazol2-yl)-2,5-diphenyltetrazolium bromide (MTT) assay was performed, as previously described (18). Briefly, 3,000 cells/well were seeded onto 96-well plates in $200 \mu \mathrm{l}$ medium. On the following day, the growth medium was replaced with vehicletreated medium (NT, untreated cultures) or with medium containing different doses of BP-14 $(5,10,25$ and $50 \mathrm{nM})$ or RAD-001 $(25,50,100$ and $150 \mathrm{nM})$ alone or in combination, as indicated in Table I. These dose ranges were selected based on previous studies $(12,19)$. The plates were incubated for 0 , 24, 48 and $72 \mathrm{~h}$. All experiments were run in quadruplicate, and cell viability was expressed as a percentage relative to the vehicle-treated cells. The percentage of cell viability was used to determine $\mathrm{EC}_{50}$ concentrations from dose-response curves, after $72 \mathrm{~h}$ of treatment.

Colony-formation assay. The clonogenic activity of the ATC cell lines was evaluated by colony-formation assay. Briefly, the cells were treated with vehicle, BP-14 and RAD-001, alone or in combination for $48 \mathrm{~h}$. FRO, SW1736 and 8505C cells were then seeded in $10-\mathrm{cm}$ plates at a density of 1,000,500 and 3,000/plate, respectively. Colonies were stained with $0.1 \%$ Coomassie Blue solution (Sigma-Aldrich) and counted using Gel Doc (Bio-Rad, Hercules, CA, USA). Data are representative of three independent experiments.

Gene expression assays. Total RNA from the human cell lines, treated either with vehicle, BP-14 at $25 \mathrm{nM}$ or RAD-001 at
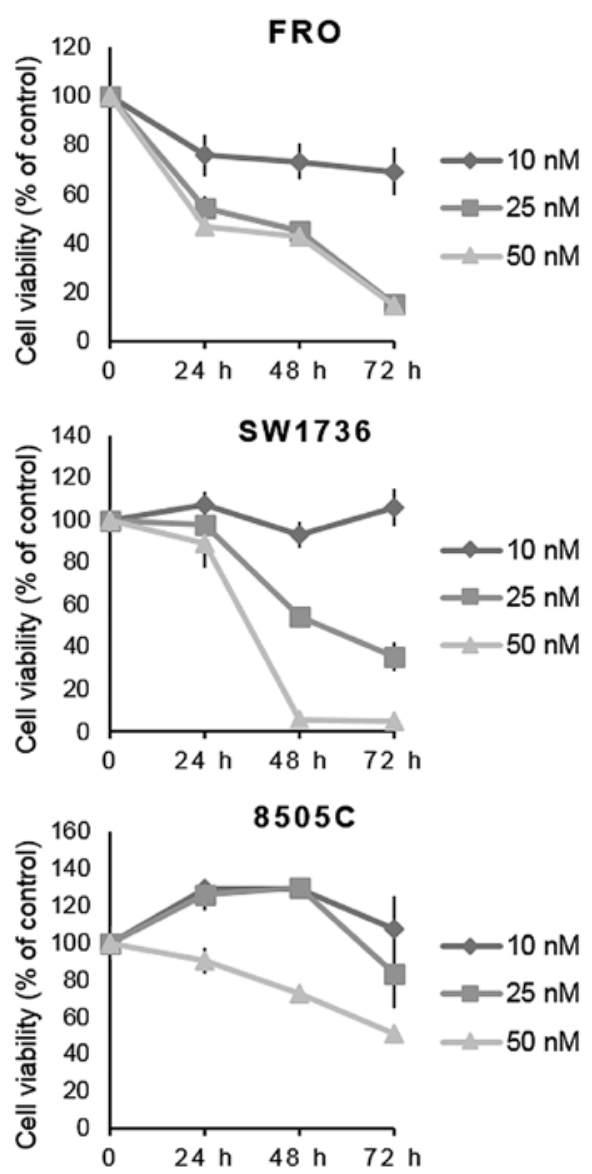

Figure 1. Administration of a CDK inhibitor decreases the viability of anaplastic thyroid carcinoma cell lines. FRO, SW1736 and 8505C cells were exposed to BP-14 at different doses (from 10 to $50 \mathrm{nM}$ ). Cell viability was determined by MTT assay after $0,24,48$ and $72 \mathrm{~h}$ and expressed as a percentage of the vehicle-treated cells. All samples were run in quadruplicate.

$100 \mathrm{nM}$, alone or in combination, was extracted with an RNeasy Mini kit according to the manufacturer's instructions (Qiagen, Hilden, Germany). Total RNA (500 ng) was reverse transcribed to cDNA using random exaprimers and SuperScript III reverse transcriptase (Life Technologies, Carlsbad, CA, USA). Real-time PCRs were performed using Platinum SYBR Green qPCR SuperMix (Life Technologies) with the ABI Prism 7300 sequence detection systems (Applied Biosystems). The $\triangle \Delta C T$ method, by means of SDS software (Applied Biosystems), was used to calculate mRNA levels. Oligonucleotide primers for $\mathrm{CDH}$ (forward, 5'-CAAATCGATGTGGATGTTTCCA-3' and reverse, 5'-CTCGCCCCGTGTGTTAGTTC-3'); VIM (forward, 5'-AGCCTCAGGTCATAAACATCATTG-3' and reverse, 5'-AGGTTCTTGGCAGCCACACT-3'); and $\beta$-actin (forward, 5'-TTGTTACAGGAAGTCCCTTGCC-3' and reverse, 5'-ATGCTATCACCTCCCCTGTGTG-3') were purchased from Sigma-Aldrich.

Combination index (CI) value. Effects of the drug combination used in this study were evaluated using the combination index (CI) equation based on the multiple drug-effect equation of Chou and Talalay $(20,21)$. In all cases where the CI value could be determined, the following diagnostic rule was 
A
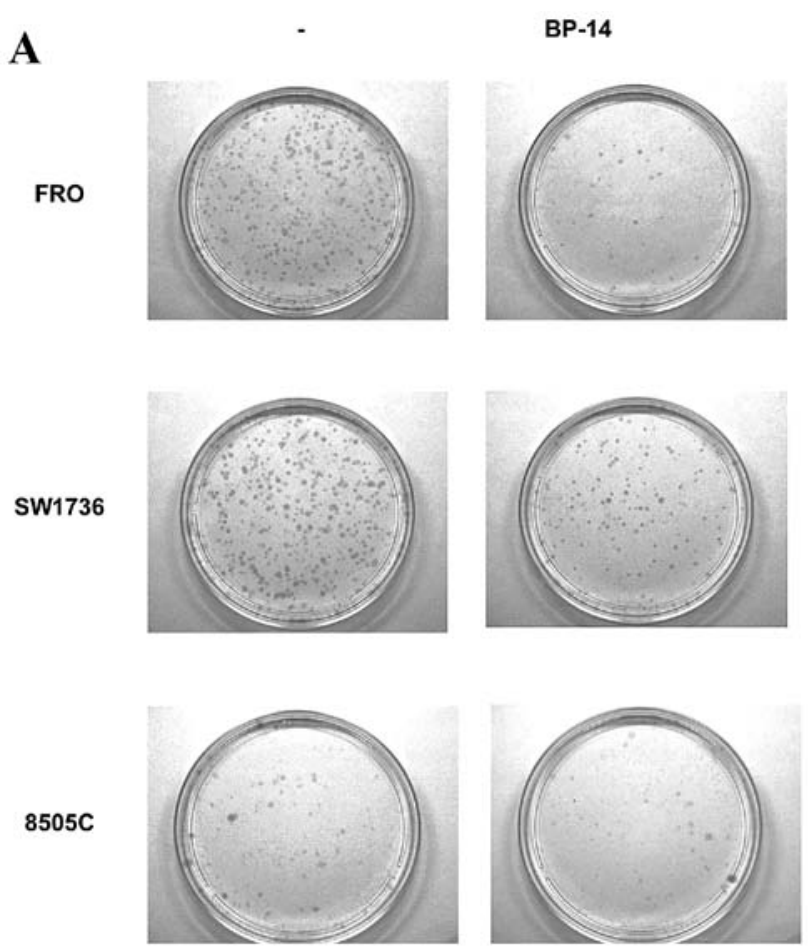

B

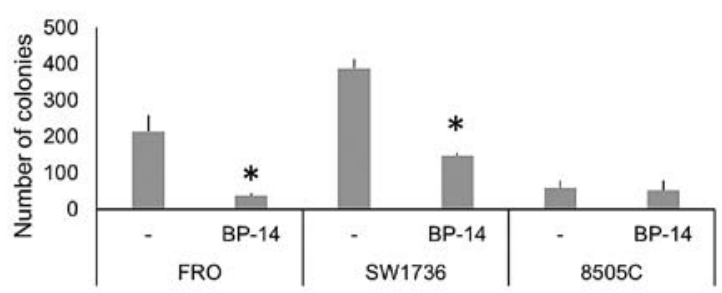

Figure 2. BP-14 treatment decreases the clonogenic ability of anaplastic thyroid carcinoma cell lines. (A) A 48-h treatment with BP-14 at $25 \mathrm{nM}$ significantly decreased colony-formation ability of the FRO and SW1736 cells. (B) Histogram represents the number of colonies per cell line. ${ }^{*} \mathrm{P}<0.05$ by Student's t-test. Data are representative of 3 independent experiments.

applied: $\mathrm{CI}<1$ indicates synergism, $\mathrm{CI}=1$ indicates an additive effect and CI $>1$ indicates antagonism. The analysis was carried out using CompuSyn software (ComboSyn Inc., Paramus, NJ, USA).

Statistical analysis. Cell viability, colony-forming capacity and evaluation of mRNA levels were expressed as means \pm SD, and significances were analyzed with the Student's t-test, performed with GraphPad Software for Science (San Diego, CA, USA).

\section{Results}

In a first set of experiments, we evaluated the biological effects of BP-14, a novel roscovitine derivate, in three human anaplastic thyroid cancer-derived cell lines (FRO, SW1736 and $8505 \mathrm{C}$ ), in a time course of treatments with different doses of BP-14. As shown in Fig. 1, incubation with different doses of BP-14 significantly reduced FRO and SW1736 cell viability, at different time-points, while it affected $8505 \mathrm{C}$ cell viability only at high doses.

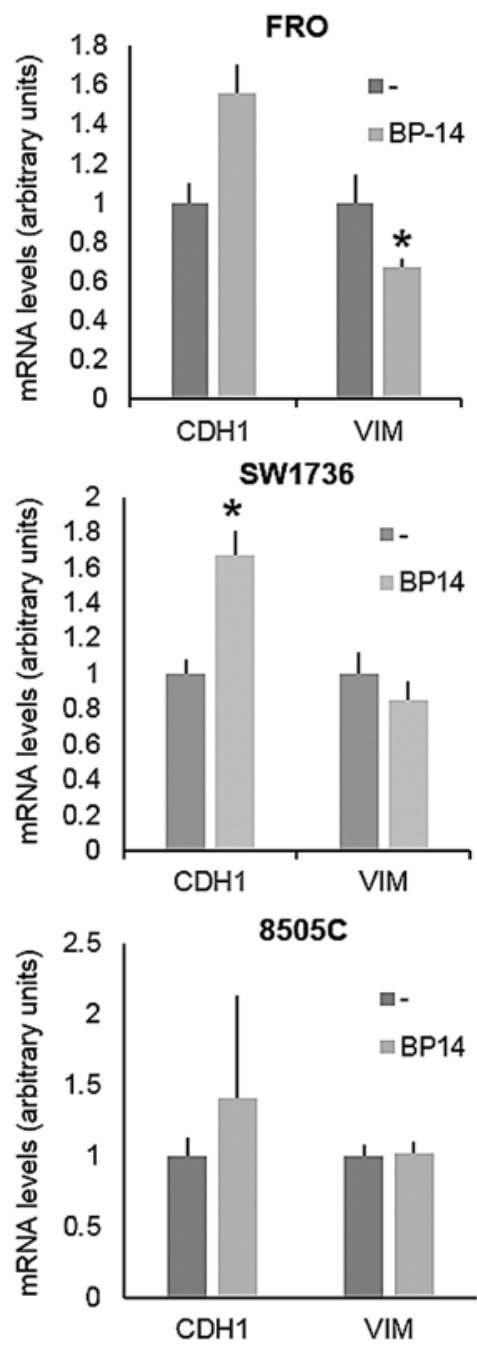

Figure 3. Expression levels of the $C D H 1$ and VIM genes in ATC cell lines after BP-14 treatment. FRO, SW1736 and 8505C cells were treated either with BP-14 at $25 \mathrm{nM}$ or vehicle for $72 \mathrm{~h}$, and $C D H 1$ and VIM mRNA expression was evaluated by qPCR. All samples were run in triplicate. ${ }^{*} \mathrm{P}<0.05$ by Student's t-test. Data are representative of 3 independent experiments.

Based on the obtained data, in further experiments, we decided to use the median effective dose of $25 \mathrm{nM}$ for a $48-\mathrm{h}$ treatment, i.e., dose and time required to achieve $50 \%$ of the theoretical maximal effect in the FRO and SW1736 cell lines.

When focusing on clonogenic activity, a 48-h treatment with BP-14 at $25 \mathrm{nM}$ reduced the number of colonies in the FRO and SW1736 cells when compared to the number of colonies in the control cells. In particular, as shown in Fig. 2, we detected a 5.5- and 3-fold reduction in the FRO and SW1736 cells, respectively. The $8505 \mathrm{C}$ cell line displayed low colony formation efficiency that was not affected by BP-14.

To further investigate the effects of BP-14 on aggressiveness parameters, we analyzed the expression of various genes involved in EMT and, in particular, we focused on $C D H 1$ and vimentin (VIM). A significant increase in $C D H 1$ gene expression was noted in the FRO and SW1736 cells (FRO, P=0.005; SW1736, $\mathrm{P}=0.002$ ), while $8505 \mathrm{C}$ cells showed no variation in CDH1 expression levels. VIM expression levels were significantly decreased only in FRO cells ( $\mathrm{P}=0.007$, Fig. 3). 
Table I. Combination index (CI) data for the combined treatment of BP-14 and RAD-001 in ATC cell lines.

\begin{tabular}{lcrccc}
\hline & $\begin{array}{c}\text { BP-14 } \\
\text { dose (nM) }\end{array}$ & $\begin{array}{c}\text { RAD-001 } \\
\text { dose (nM) }\end{array}$ & $\begin{array}{c}\text { CI in } \\
\text { FRO }\end{array}$ & $\begin{array}{c}\text { CI in } \\
\text { SW1736 }\end{array}$ & $\begin{array}{c}\text { CI in } \\
8505 \text { C }\end{array}$ \\
\hline Point 1 & 5.0 & 25.0 & 0.30202 & $1.097 \mathrm{E} 8$ & 18596.3 \\
Point 2 & 5.0 & 50.0 & 2.12135 & 0.39369 & 0.05979 \\
Point 3 & 5.0 & 100.0 & 3.73150 & 0.50684 & 0.52049 \\
Point 4 & 5.0 & 150.0 & 5.34166 & 0.94557 & 0.05011 \\
Point 5 & 10.0 & 25.0 & 0.31318 & 0.69159 & 305.585 \\
Point 6 & 10.0 & 50.0 & 0.50569 & 0.33884 & 0.12378 \\
Point 7 & 10.0 & 100.0 & 4.24271 & 0.47682 & 6.17151 \\
Point 8 & 10.0 & 150.0 & 0.26274 & 0.91167 & 0.10012 \\
Point 9 & 25.0 & 25.0 & 0.55719 & 15.6815 & 0.22520 \\
Point 10 & 25.0 & 50.0 & 0.52671 & 0.36697 & 0.24538 \\
Point 11 & 25.0 & 100.0 & 0.63991 & 0.55161 & 0.24814 \\
Point 12 & 25.0 & 150.0 & 0.54472 & 0.98968 & 0.34295 \\
Point 13 & 50.0 & 25.0 & 1.00195 & 3.44322 & 0.43611 \\
Point 14 & 50.0 & 50.0 & 0.98965 & 0.35021 & 0.46149 \\
Point 15 & 50.0 & 100.0 & 1.04564 & 0.54217 & 0.50288 \\
Point 16 & 50.0 & 150.0 & 0.96844 & 0.97197 & 0.41918 \\
\hline
\end{tabular}

Since a promising approach to cancer therapy is the combined use of different drugs, we evaluated whether BP-14 interacts synergistically with other compounds already used in cancer treatment, such as everolimus (RAD-001). For this purpose, we evaluated the effect of a combined treatment of BP14 and RAD-001 by measuring the CI values, according to the Chou and Talalay equation $(20,21)$. The two-drug combination elicited a strong decrease in cell viability, compared to the untreated cells (CI values were <1) (Table I and Figs. 4 and 5). Our results revealed that BP-14 and RAD-001 exhibited a synergistic effect in decreasing cell proliferation at a quite high range of doses in all three ATC cell lines.

Then, we evaluated changes in EMT-related processes, i.e. colony formation as well as $C D H 1$ and VIM gene expression, after a combined treatment with BP-14 at $25 \mathrm{nM}$ and RAD-001 at $100 \mathrm{nM}$. A 48-h BP-14 treatment significantly reduced colony formation in the $\mathrm{FRO}(\mathrm{P}=0.0002)$ and $\mathrm{SW} 1736$ $(\mathrm{P}=0.004)$ cells (comparison of Fig. 2 and 6A). The treatment with RAD-001 at $100 \mathrm{nM}$ reduced the clonogenic ability only in the SW1736 cells $(\mathrm{P}=0.027)$. In contrast, the combined treatment significantly reduced the clonogenic capacity of the FRO $(\mathrm{P}=0.0007)$ and $\mathrm{SW} 1736(\mathrm{P}=0.0002)$ cells. The $8505 \mathrm{C}$ cells displayed, again, no benefit after either BP-14 or RAD-001 treatment, alone or in combination.

Following analysis of the expression of EMT-related genes, treatment with BP-14 at $25 \mathrm{nM}$ increased the $\mathrm{CDH} 1$ mRNA level in the FRO $(\mathrm{P}=0.005)$ and SW1736 $(\mathrm{P}=0.002)$ cells and reduced the VIM mRNA level only in the FRO cells $(\mathrm{P}=0.007)$ (comparison of Fig. 3 and 6B). Treatment with RAD-001 at $100 \mathrm{nM}$ modestly modified $\mathrm{CDH1}$ (FRO, $\mathrm{P}=0.006$; $\mathrm{SW} 1736, \mathrm{P}=0.0047 ; 8505 \mathrm{C}, \mathrm{P}=0.02$ ) and VIM (FRO, $\mathrm{P}=\mathrm{ns} ; \mathrm{SW} 1736, \mathrm{P}=0.007 ; 8505 \mathrm{C}, \mathrm{P}=\mathrm{ns}) \mathrm{mRNA}$ levels in all
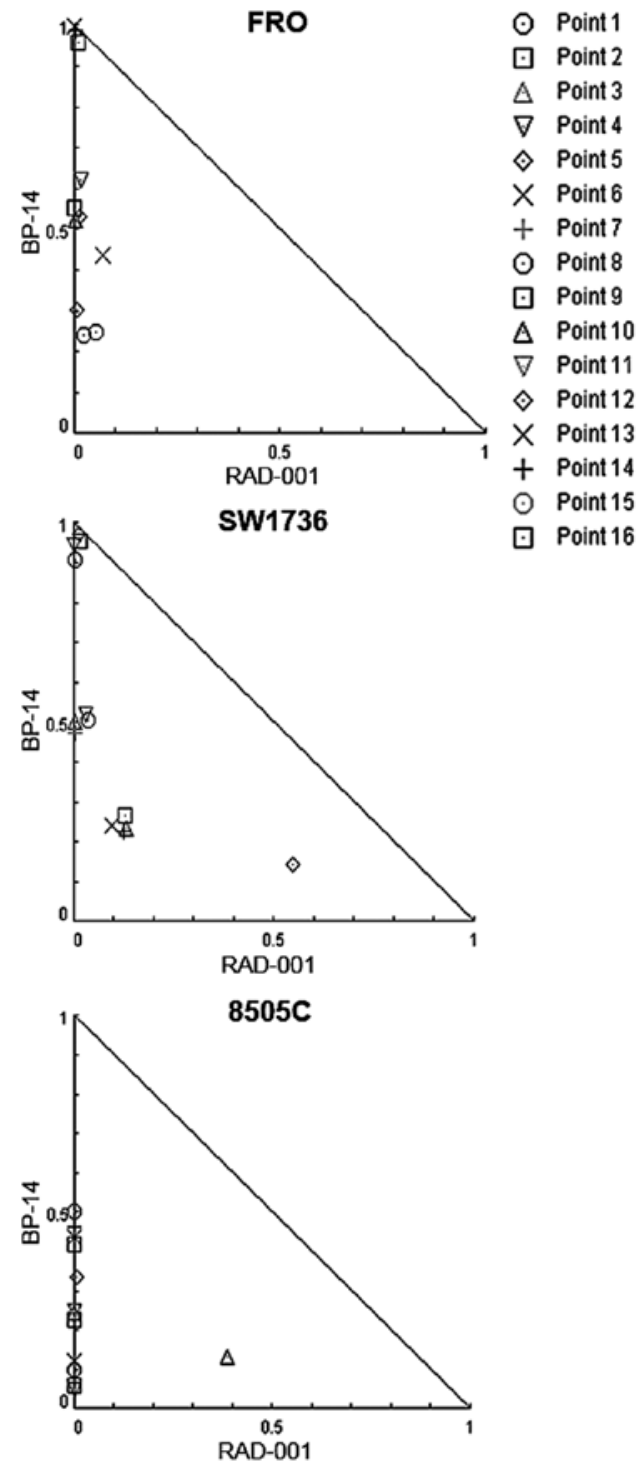

Figure 4. Synergistic effect of the combined treatment of a CDK inhibitor and an mTOR inhibitor in ATC cell lines. Normalized isobolograms representing FRO, SW1736 and $8505 \mathrm{C}$ cell viability after a 48 -h treatment with different doses of BP-14 (from 5 to $50 \mathrm{nM}$ ) and RAD-001 (from 25 to $150 \mathrm{nM}$ ).

three cell lines. The synergistic treatment with BP-14 and RAD-001 greatly increased the $C D H 1$ mRNA level in the $8505 \mathrm{C}(\mathrm{P}=0.0003)$, so far considered 'unresponsive' to single agent treatment.

\section{Discussion}

The search for new target therapies for ATC is urgently needed. In fact, this neoplasm, although a rare histotype of thyroid cancer, is characterized by an extremely poor prognosis (22). The complete loss of differentiation makes it unresponsive to radioiodine treatment (23), and current treatments, based on a combination of surgery, chemotherapy and external radiotherapy, are not effective. The discovery of molecular alterations occurring in such tumors, has permitted the selection of a series of novel agents able to act against such molecular targets. For an initial screening of these novel potential drugs, several human ATC cell lines, which carry the 

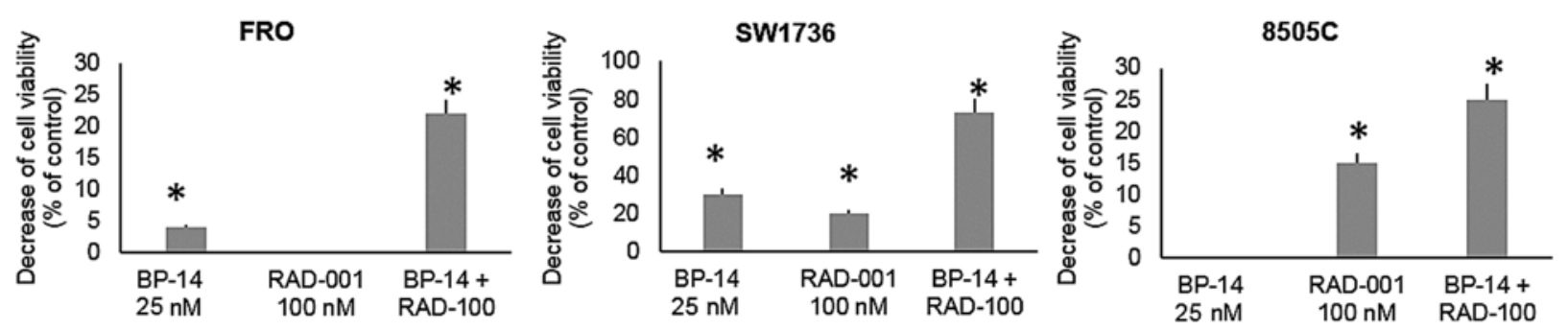

Figure 5. Effect of the combined treatment of BP-14 at $25 \mathrm{nM}$ and RAD-001 at $100 \mathrm{nM}$ on ATC cell viability. Cells were treated for $48 \mathrm{~h}$ with BP-14 at $25 \mathrm{nM}$ and RAD-001 at $100 \mathrm{nM}$, alone or in combination. Bars indicate the percentage of viable cells vs. control (vehicle-treated cells). "P<0.0001 by Student's t-test. Data are representative of 3 independent experiments.

A

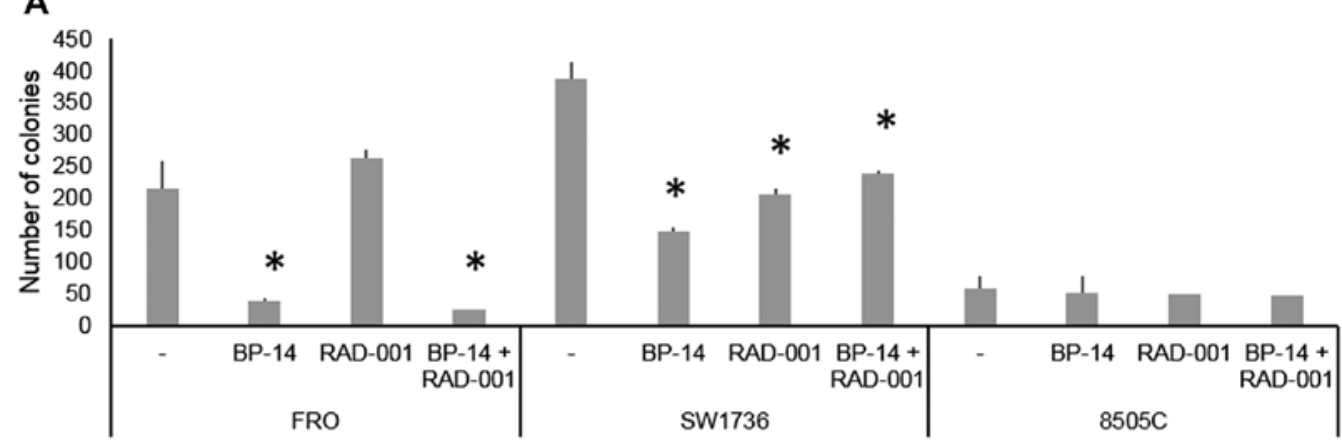

B 4 FRO
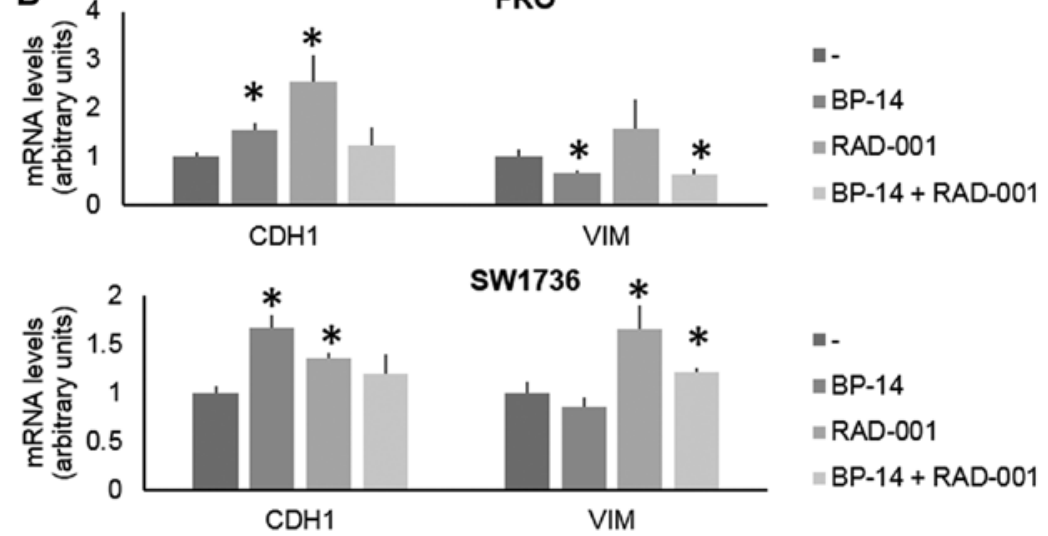

II-

-BP-14

$=$ RAD-001

$=B P-14+$ RAD-001

$8505 \mathrm{C}$
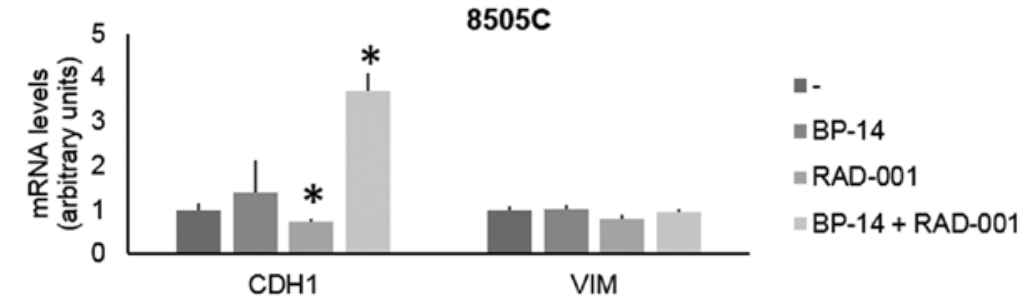

Figure 6. Synergy of a combined treatment of BP-14 and RAD-001 on EMT-related phenomena in anaplastic thyroid carcinoma cell lines. (A) A 48-h combined treatment with BP-14 at $25 \mathrm{nM}$ and RAD-001 at $100 \mathrm{nM}$ significantly decreased the colony-formation ability of FRO and SW1736 cells. (B) FRO, SW1736 and $8505 \mathrm{C}$ cells were treated either with BP-14 at $25 \mathrm{nM}$ or RAD-001 at $100 \mathrm{nM}$, alone or in combination, for $72 \mathrm{~h}$ and $C D H 1$ and VIM mRNA expression was evaluated by qPCR. All samples were run in triplicate. ${ }^{*} \mathrm{P}<0.05$ by Student's t-test. Data are representative of 3 independent experiments.

same genetic and epigenetic alterations of human neoplasias, have been largely exploited.

Among the inhibitors affecting major oncogenic pathways, the most attractive are those targeting the kinases involved in cell cycle regulation (24). Since data indicate that CDKs and CDKIs play a role in thyroid tumorigenesis (25-27), we focused on the efficacy of a novel compound, BP-14, which is able to antagonize CDK1/2/5/7 and CDK9 (14). Apart from 'in vitro' effects, using cultured cell lines $(12,14), \mathrm{BP}-14$ has been previously investigated 'in vivo' using xenografts derived from hepatoma cell lines and chemically induced liver cancer (14). By these approaches, it has been demonstrated that, at the dose of $1 \mathrm{mg} / \mathrm{kg}$, BP-14 significantly reduces tumor growth without any side effects. We showed that BP-14 affected the viability of three different ATC cell lines at very similar concentrations to those active in hepatoma cells (14): $25 \mathrm{nM}$ for FRO and 
SW1736 cells and $50 \mathrm{nM}$ for $8505 \mathrm{C}$ cells. Therefore, considering data obtained 'in vitro' and 'in vivo' with hepatoma cells, our findings suggest that BP-14 could be used 'in vivo' for ATC treatment.

A major finding in our resarch was the demonstration of synergy between BP-14 and the mTOR inhibitor everolimus. In fact, in all three ATC cell lines analyzed, the combined use of BP-14 and everolimus significantly decreased cell viability to a greater extent than using the two compounds alone. The simultaneous use of compounds targeting distinct signaling pathways appears to be a very efficient anticancer strategy (28). Accordingly, previous research has demonstrated 'in vivo' the synergy between mTOR and MAPK inhibitors (29). Since the combination of distinct molecular drugs appears to be quite effective in ATC (30), our data would indicate a novel strategy for treatment of this type of tumor.

\section{Acknowledgements}

The present study was supported by grants to G.D. from Associazione Italiana per la Ricerca sul Cancro (AIRC) (project no. IG 10296) and to V.K. from the Czech Science Foundation (grant no. 15-152645).

\section{References}

1. Pellegriti G, Frasca F, Regalbuto C, Squatrito $S$ and Vigneri R Worldwide increasing incidence of thyroid cancer: Update on epidemiology and risk factors. J Cancer Epidemiol 2013: 965212, 2013.

2. O'Neill JP and Shaha AR: Anaplastic thyroid cancer. Oral Oncol 49: 702-706, 2013.

3. Kojic SL, Strugnell SS and Wiseman SM: Anaplastic thyroid cancer: A comprehensive review of novel therapy. Expert Rev Anticancer Ther 11: 387-402, 2011.

4. Wang HM, Huang YW, Huang JS, Wang CH, Kok VC, Hung CM, Chen HM and Tzen CY: Anaplastic carcinoma of the thyroid arising more often from follicular carcinoma than papillary carcinoma. Ann Surg Oncol 14: 3011-3018, 2007.

5. Quiros RM, Ding HG, Gattuso P, Prinz RA and Xu X: Evidence that one subset of anaplastic thyroid carcinomas are derived from papillary carcinomas due to BRAF and p53 mutations. Cancer 103: 2261-2268, 2005.

6. Liu Z, Hou P, Ji M, Guan H, Studeman K, Jensen K, Vasko V, El-Naggar AK and Xing M: Highly prevalent genetic alterations in receptor tyrosine kinases and phosphatidylinosito 3-kinase/akt and mitogen-activated protein kinase pathways in anaplastic and follicular thyroid cancers. J Clin Endocrinol Metab 93: 3106-3116, 2008.

7. Mendoza MC,ErEE and Blenis J: The Ras-ERK and PI3K-mTOR pathways: Cross-talk and compensation. Trends Biochem Sci 36: 320-328, 2011.

8. McCubrey JA, Steelman LS, Abrams SL, Lee JT, Chang F, Bertrand FE, Navolanic PM, Terrian DM, Franklin RA D'Assoro AB, et al: Roles of the RAF/MEK/ERK and $\mathrm{PI} 3 \mathrm{~K} / \mathrm{PTEN} / \mathrm{AKT}$ pathways in malignant transformation and drug resistance. Adv Enzyme Regul 46: 249-279, 2006.

9. Russo D, Damante G, Puxeddu E, Durante C and Filetti S: Epigenetics of thyroid cancer and novel therapeutic targets. J Mol Endocrinol 46: R73-R81, 2011.

10. Tallini G, Garcia-Rostan G, Herrero A, Zelterman D, Viale G, Bosari S and Carcangiu ML: Downregulation of $\mathrm{p} 27^{\mathrm{KIP} 1}$ and Ki67/Mib1 labeling index support the classification of thyroid carcinoma into prognostically relevant categories. Am J Surg Pathol 23: 678-685, 1999.
11. Pita JM, Figueiredo IF, Moura MM, Leite V and Cavaco BM: Cell cycle deregulation and TP53 and RAS mutations are major events in poorly differentiated and undifferentiated thyroid carcinomas. J Clin Endocrinol Metab 99: E497-E507, 2014

12. Gucký T, Jorda R, Zatloukal M, Bazgier V, Berka K, RezníčkováE, Béres T, Strnad M and Kryštof V: A novel series of highly potent 2,6,9-trisubstituted purine cyclin-dependent kinase inhibitors. J Med Chem 56: 6234-6247, 2013.

13. Hersey P, Bastholt L, Chiarion-Sileni V, Cinat G, Dummer R, Eggermont AM, Espinosa E, Hauschild A, Quirt I, Robert C, et al: Small molecules and targeted therapies in distant metastatic disease. Ann Oncol 20 (Suppl 6): vi35-vi40, 2009.

14. Haider C, Grubinger M, Rezníčková E, Weiss TS, Rotheneder H, Miklos W, Berger W, Jorda R, Zatloukal M, Gucky T, et al: Novel inhibitors of cyclin-dependent kinases combat hepatocellular carcinoma without inducing chemoresistance. Mol Cancer Ther 12: 1947-1957, 2013.

15. Polyak K and Weinberg RA: Transitions between epithelial and mesenchymal states: Acquisition of malignant and stem cell traits. Nat Rev Cancer 9: 265-273, 2009.

16. Pilli T, Prasad KV, Jayarama S, Pacini F and Prabhakar BS: Potential utility and limitations of thyroid cancer cell lines as models for studying thyroid cancer. Thyroid 19: 1333-1342, 2009.

17. Schweppe RE, Klopper JP, Korch C, Pugazhenthi U, Benezra M, Knauf JA, Fagin JA, Marlow LA, Copland JA, Smallridge RC, et al: Deoxyribonucleic acid profiling analysis of 40 human thyroid cancer cell lines reveals cross-contamination resulting in cell line redundancy and misidentification. J Clin Endocrinol Metab 93: 4331-4341, 2008

18. Baldan F, Lavarone E, Di Loreto C, Filetti S, Russo D, Damante G and Puppin C: Histone post-translational modifications induced by histone deacetylase inhibition in transcriptional control units of NIS gene. Mol Biol Rep 41: 5257-5265, 2014.

19. Papewalis C, Wuttke M, Schinner S, Willenberg HS, Baran AM, Scherbaum WA and Schott M: Role of the novel mTOR inhibitor RAD001 (everolimus) in anaplastic thyroid cancer. Horm Metab Res 41: 752-756, 2009.

20. Chou TC and Talalay P: Analysis of combined drug effects: A new look at a very old problem. Trends Pharmacol Sci 4: 450-454, 1983.

21. Chou TC and Talalay P: Quantitative analysis of dose-effect relationships: The combined effects of multiple drugs or enzyme inhibitors. Adv Enzyme Regul 22: 27-55, 1984.

22. Denaro N, Nigro CL, Russi EG and Merlano MC: The role of chemotherapy and latest emerging target therapies in anaplastic thyroid cancer. Onco Targets Ther 9: 1231-1241, 2013.

23. Schlumberger M, Lacroix L, Russo D, Filetti S and Bidart JM: Defects in iodide metabolism in thyroid cancer and implications for the follow-up and treatment of patients. Nat Clin Pract Endocrinol Metab 3: 260-269, 2007.

24. Senderowicz AM: Targeting cell cycle and apoptosis for the treatment of human malignancies. Curr Opin Cell Biol 16: 670-678, 2004.

25. Wang S, Wuu J, Savas L, Patwardhan $\mathrm{N}$ and Khan A: The role of cell cycle regulatory proteins, cyclin D1, cyclin E, and p27 in thyroid carcinogenesis. Hum Pathol 29: 1304-1309, 1998.

26. Elisei R, Shiohara M, Koeffler HP and Fagin JA: Genetic and epigenetic alterations of the cyclin-dependent kinase inhibitors p $15^{\text {INK4b }}$ and $\mathrm{p} 16^{\mathrm{INK} 4 \mathrm{a}}$ in human thyroid carcinoma cell lines and primary thyroid carcinomas. Cancer 83: 2185-2193, 1998.

27. Rocha AS, Paternot S, Coulonval K, Dumont JE, Soares P and Roger PP: Cyclic AMP inhibits the proliferation of thyroid carcinoma cell lines through regulation of CDK4 phosphorylation. Mol Biol Cell 19: 4814-4825, 2008.

28. Li F, Zhao C and Wang L: Molecular-targeted agents combination therapy for cancer: Developments and potentials. Int J Cancer 134: 1257-1269, 2014.

29. Carracedo A, Baselga J and Pandolfi PP: Deconstructing feedback-signaling networks to improve anticancer therapy with mTORC1 inhibitors. Cell Cycle 7: 3805-3809, 2008.

30. Perri F, Lorenzo GD, Scarpati GD and Buonerba C: Anaplastic thyroid carcinoma: A comprehensive review of current and future therapeutic options. World J Clin Oncol 2: 150-157, 2011. 